\title{
Anterograde Amnesia after Acute Glufosinate Ammonium Intoxication
}

\author{
Hyuk-Hoon Kim and Young-Gi Min
}

Department of Emergency Medicine, Ajou University School of Medicine, Suwon, Korea

Glufosinate ammonium (GA) intoxication causes several neurologic complications. We report a rare but typical case of GA intoxication associated with anterograde amnesia and bilateral hippocampal involvement. A 53-year-old woman with GA intoxication presented to the emergency department. Initial general and neurologic examinations were unremarkable but, from the day after admission, she exhibited anterograde amnesia. On brain magnetic resonance imaging, the signal intensity in the hippocampus was symmetrically and bilaterally increased. She was discharged with no medical problems, but the anterograde amnesia remained. Eleven days after the onset of amnesia, she returned to the neurology outpatient department with persisting anterograde amnesia but improving symptoms.

Key Words: ammonia; amnesia; herbicides; hippocampus

Glufosinate ammonium (GA) is a commercial herbicide that causes several neurologic complications such as loss of consciousness, convulsions, and memory impairment [1]. The N-methyl-D-aspartate (NMDA)-type glutamate receptor in the hippocampus is the main target for GA, and its binding to this receptor is implicated in the toxic anterograde amnesia effects of GA $[2,3]$. We report a rare but typical case of anterograde amnesia and bilateral hippocampal involvement in acute GA intoxication.

\section{CASE REPORT}

A 53-year-old woman with no previous medical history presented to the emergency department 9 hours after drinking $200 \mathrm{ml}$ of GA and trying to hang herself as a suicide attempt. Formulation of the herbicide was as follows: GA, 18\%; alcohol (C12-14), ethoxylated monoether with sulfuric acid, and sodium salts (CAS No. 68909-66-0) as surfactants, $28.5 \%$; antifoaming agent and coloring agent, $0.5 \%$; and water, $53 \%$. When presented to the emergency department, she was slightly drowsy but had no symptoms or signs of gastrointestinal irritation. An external wound-like bruise was not seen on the head or neck. The vital signs were stable. Arterial blood gas determination showed slight metabolic and re-

Received on May 13, 2016 Revised on July 28, 2016 Accepted on September 5, 2016

Correspondence to: Young-Gi Min, Department of Emergency Medicine, Ajou University Hospital, 164 World cup-ro, Yeongtong-gu, Suwon 16499, Korea Tel: +82-31-219-7750, Fax: +82-31-219-7760, E-mail: youngmd@ajou.ac.kr

*No potential conflict of interest relevant to this article was reported.

cc This is an Open Access article distributed under the terms of the Creative Commons Attribution Non-Commercial License (http://creativecommons.org/ licenses/by-nc/4.0/) which permits unrestricted non-commercial use, distribution, and reproduction in any medium, provided the original work is properly cited. Copyright (c) 2018 The Korean Society of Critical Care Medicine 
spiratory acidosis with a $\mathrm{pH}$ of $7.31, \mathrm{PO}_{2}$ of $79.6 \mathrm{mmHg}$, $\mathrm{PCO}_{2}$ of $46.2 \mathrm{mmHg}$, and $\mathrm{HCO}_{3}$ of $22.5 \mathrm{mmol} / \mathrm{L}$. The serum ammonium level was $308 \mu \mathrm{M}$. The general and neurologic examinations were unremarkable, except for drowsy mentality and increased irritability. She immediately received gastric lavage followed by charcoal and was admitted to the emergency intensive care unit. On hospital day 1 , she could not remember that she had been admitted to the hospital. She was unable to remember things she had just been told, but she could recall events of decades ago; she did not understand why she had been admitted to the hospital despite being told repeatedly by her family. She could not recall people who had recently visited her, even the doctors and nurses. On hospital day 4 , she became alert and her medical condition was normal except for persistent amnesia. So, she was referred to the Neurology Department for further assessment of her anterograde amnesia. On neurologic examination, motor and sensory function was intact, and extrapyramidal signs and symptoms were evaluated, such as abnormal movement or tonic abnormalities of muscles. On the Mini-Mental State Examination, she scored 24 of 30 points. She lost 2 points in the category of "Orientation to time," 1 point in the category of "Orientation to place," and 3 points in the category of "Registration recall." On hospital day 6, brain magnetic resonance imaging (MRI) was performed and showed symmetric, bilateral increase in signal intensity in the hippocampus on fluid-attenuated inversion recovery and T2-weighted images (Figure 1). On hospital day 8, waking and sleep electroencephalogram was recorded and interpreted as normal for the patient. On hospital day 9 , she was discharged with no medical problems except anterograde amnesia. Eleven days after the onset of amnesia, she reported back to the neurology outpatient department, where her anterograde amnesia was evaluated and still present, but was slowly improving.

\section{DISCUSSION}

The hippocampus is the main structure in the brain that is responsible for learning and memory. Also, the hippocampus is a plastic and vulnerable structure that can be damaged by a variety of stimuli and is affected by a variety of neurological and psychiatric disorders [4]. In several cases of anterograde amnesia after GA intoxication, brain MRI showed hyper-signal intensity in the hippocampus, and this injury can be explained by overstimulation of the glutamate-NMDA receptor caused by glufosinate, which acts similar to glutamate in the hippocampus [1,5]. This may result in memory loss, especially anterograde amnesia, as in this case. Moreover, the increasing concentration of nitric oxide followed by
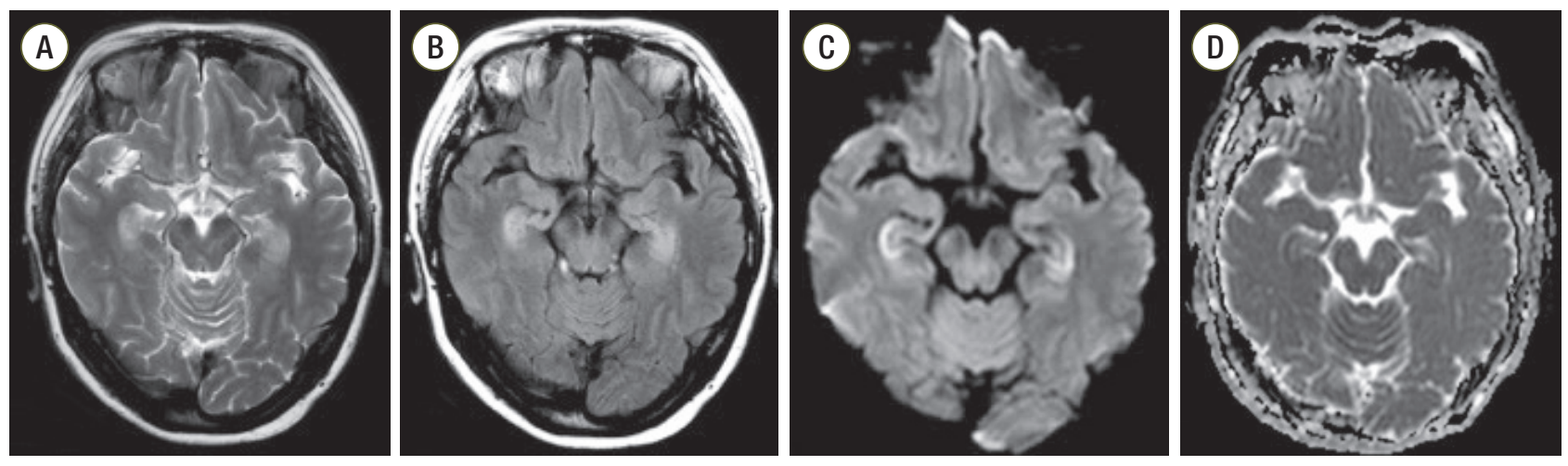

Figure 1. Brain magnetic resonance imaging (MRI) on the sixth day following glufosinate ammonium intoxication. Brain MRI revealed symmetric and bilateral increases in signal intensity in the hippocampus on (A) T2-weighted images and (B) fluid-attenuated inversion recovery images. This lesion exhibited hyperintensity on (C) diffusion-weighted imaging and hypointensities on (D) apparent diffusion coefficient mapping. 
hyperammonemia causes oxidative stress in the central nervous system. As in our case, hyper-ammonemia in GA intoxication could also lead to injury of the hippocampus and result in amnesia [6-9].

However, cases that show typical anterograde amnesia with a focal insult of the hippocampus on MRI after GA intoxication are very rare. Almost all cases of GA intoxication report general signs and symptoms of generalized tonic-clonic seizure, respiratory hold, severe deterioration in cognitive function, and encephalopathy [10-14]. One reason why this case was different from the other cases in regard to general signs and symptoms is that the GA doses were different. The GA dose in this case study was approximately half those in other case reports. This indicates variability of symptoms according to GA dose, and symptom and toxicity predictions can be made along the course of GA intoxication in patients depending on the dose ingested.

In addition, the hanging attempt could have also contributed to hippocampus injury and resulted in amnesia. Hanging induces ischemic damage in the brain, and the hippocampus is one of the most vulnerable organs in the brain in ischemic injury. In one experiment, pyramidal cells of a CA1 lesion in the hippocampus decreased after intentional hypoxic hanging injury in rats [15]. This decrease in cell count caused by cell death in the hippocampus may have contributed to amnesia symptoms associated with hanging. Considering that behavior and personal changes are much more common in serious hanging incidents due to injuries of watershed cerebral cortex and basal ganglia and more widespread brain damage, the hanging event was likely mild and brief in this case [16].

To the best of our knowledge, there is not an antidote generally used in the treatment of GA intoxication. The neurologic symptoms of GA are mainly explained by overstimulation of NMDA receptors. So, the modulation of NMDA and glutamate may be explored in the development of an antidote for GA intoxication. Also, considering the neurotoxicity of hyperammonemia, procedures for reducing serum ammonia could be applied to GA intoxication patients, similar to those used to treat hyperammonemia in liver failure patients.

\section{ORCID}

Hyuk-Hoon Kim https://orcid.org/0000-0003-1957-3020

Young-Gi Min https://orcid.org/0000-0003-0930-5997

\section{REFERENCES}

1. Park HY, Lee PH, Shin DH, Kim GW. Anterograde amnesia with hippocampal lesions following glufosinate intoxication. Neurology 2006;67:914-5.

2. Calas AG, Richard O, Même S, Beloeil JC, Doan BT, Gefflaut T, et al. Chronic exposure to glufosinate-ammonium induces spatial memory impairments, hippocampal MRI modifications and glutamine synthetase activation in mice. Neurotoxicology 2008;29:740-7.

3. Meme S, Calas AG, Montécot C, Richard O, Gautier $\mathrm{H}$, Gefflaut T, et al. MRI characterization of structural mouse brain changes in response to chronic exposure to the glufosinate ammonium herbicide. Toxicol Sci 2009;111:321-30.

4. Anand KS, Dhikav V. Hippocampus in health and disease: an overview. Ann Indian Acad Neurol 2012;15:239-46.

5. Haberny KA, Paule MG, Scallet AC, Sistare FD, Lester DS, Hanig JP, et al. Ontogeny of the N-methyl-D-aspartate (NMDA) receptor system and susceptibility to neurotoxicity. Toxicol Sci 2002;68:9-17.

6. Kosenko E, Kaminsky Y, Lopata O, Muravyov N, Kaminsky A, Hermenegildo C, et al. Nitroarginine, an inhibitor of nitric oxide synthase, prevents changes in superoxide radical and antioxidant enzymes induced by ammonia intoxication. Metab Brain Dis 1998;13:29-41.

7. Kosenko E, Kaminsky Y, Kaminsky A, Valencia M, Lee L, Hermenegildo C, et al. Superoxide production 
and antioxidant enzymes in ammonia intoxication in rats. Free Radic Res 1997;27:637-44.

8. Koruk M, Aksoy H, Akçay F, Onuk MD. Antioxidant capacity and nitric oxide in patients with hepatic cirrhosis. Ann Clin Lab Sci 2002;32:252-6.

9. Ranganathan S, Sundaresan S, Raghavendra I, Kalyani S. Dry mixing technique for the large scale production of iodine fortified salt in India. Asia Pac J Clin Nutr 1997;6:92-4.

10. Tanaka J, Yamashita M, Yamashita M, Matsuo H, Yamamoto T. Two cases of glufosinate poisoning with late onset convulsions. Vet Hum Toxicol 1998;40:219-22.

11. Park JS, Kwak SJ, Gil HW, Kim SY, Hong SY. Glufosinate herbicide intoxication causing unconsciousness, convulsion, and 6th cranial nerve palsy. J Korean Med Sci 2013;28:1687-9.

12. Calas AG, Perche O, Richard O, Perche A, Pâris A, Lauga $F$, et al. Characterization of seizures induced by acute exposure to an organophosphate herbicide, glufosinate-ammonium. Neuroreport 2016;27:53241.

13. Youn SW, Kim HK, LEE HJ. A case of anterograde amnesia with bilateral hippocampus involvement after acute glufosinate ammonium intoxication. J Korean Soc Magn Reson Med 2014;18:352-6.

14. Wi DH, Chang H. Treatment of status epilepticus following glufosinate ammonium intoxication. J Korean Epilepsy Soc 2007;11:113-5.

15. Cenger CD, Kurtulus A, Acar K, Boz B. Presentation of the change in the number of hippocampal neurons by stereological method in surviving cases of mechanical asphyxia: an experimental rat study. Rom J Leg Med 2012;20:95-100.

16. Caine D, Watson JD. Neuropsychological and neuropathological sequelae of cerebral anoxia: a critical review. J Int Neuropsychol Soc 2000;6:86-99. 